\title{
Experimental Measurement of Rice Husk Effectiveness as an Alternative Adsorbent for Turbidity Reduction in Synthetic Water
}

\begin{abstract}
1) Civil Engineering Department, College of Engineering, Al-Nahrain University, P.O. Box 64040 Jadriya - Baghdad - Iraq, nano 8098@yahoo.com \section{Department, Faculty of Zakho, Zakho International Road, Zakho-Duhok, samara.saad2017@gmail.com}

2) Environmental Science Science, University of Kurdistan Region - Iraq.
\end{abstract}

\section{Paper History:}

Received: 16 $6^{\text {th }}$ Oct. 2019

Revised: $17^{\text {th }}$ Nov. 2019

Accepted: 11 th Dec. 2019

\author{
Noora Saad Faraj ${ }^{1, *}$, Samara Saad Faraj ${ }^{2}$
}

\begin{abstract}
Providing a clean and high quality drinking water to both rural as well as urban areas is a great challenge by itself, adding to it the large volume requirements of such water at high population areas means a very high cost for such industry because mainly of the cost of expensive commercially available adsorbent used in this process. This led inhabitants of the remote and/or rural areas to use less quality water with all its risks and health challenges. In this study, a locally collected rice husk is tested to be used as an alternative adsorbent to the expensive common commercial ones. Parameters like adsorbent dosage, initial concentration of turbidity, and $\mathrm{pH}$ level were tested to investigate their effects on the process. Treatment of synthetic turbid water was done after changing these parameters to measure the effect of each parameter alone and the results showed a set of parameters that can be used to achieve high efficiency of turbidity removal. The study concluded that rice husk can be used as a well cheap alternative adsorbent to reduce the river water turbidity due to its availability and low cost with a decent removal efficiency approaching 95\%.
\end{abstract}

Keywords: Turbidity; Rice husk; Adsorption; Adsorbent Dosage; Turbidity Initial Concentration; $\mathrm{pH}$ level.

$$
\begin{aligned}
& \text { القياس التجريبي لفعالية قشور الأرز كمادة مازة بديلة لتقليل العكورة في المياه } \\
& \text { الإصطناعية } \\
& \text { نورا سعد فرج، سمارة سعد فرج }
\end{aligned}
$$

\section{Introduction}

One of the increasingly limiting resources in the planet nowadays is the fresh water, more reduction and an increase in the limitation is expected in the next century. This increase results due to urbanization, climate change and population inflation, which may lead to water crisis among other environmental serious consequences. The increase in the drinking water need will not be effected by such limitation only but also by the pollution resulted from the factors mentioned earlier on the freshwater ecosystem. (Al-Baidhani and Al-Salihy, 2016)

In the developing countries likewise in many other parts in the world, the fresh surface water is considered as the main water supply source. Drinking water in specific is usually extracted from the highly turbid river

NJES is an open access Journal with ISSN 2521-9154 and eISSN 2521-9162

This work is licensed under a Creative Commons Attribution-NonCommercial 4.0 International License 
water. Recent survey showed that more than 880 million people cannot have access to clean and improved drinking water worldwide, majority of this number live in rural and remote communities in those developing countries (WHO/UNICEF 2010).

Turbidity has been defined by many agencies, including United States Environmental Protection Agency USEPA, as the cloudiness of water and a measure to indicate the quality of water. It is known that the concentrations of clay and other suspended solids is very high in the surface water. This is considered the main problem facing the usage of such water sources as drinking water, taking into account that such environment is considered the best habitat for organic compounds and disease-causing microorganisms (such as viruses, parasites and some bacteria) such organisms are the main reasons for symptoms like nausea, cramps, diarrhea (WHO, 2007). The permissible limit for treated water in Iraq is 5 NTU according to Iraqi standards (Alwared and Zeki, 2014). A significant attention has been focused on Turbidity removal from aqueous solution using adsorbent derived from low-cost materials like agricultural waste and by-products, such as Cucurbita pepo Seed Powder (Yunusa et al,2017), Banana peel (John et al, 2017), fly ash (Syafalni, et al 2013). This study aims to evaluate the performance of rice husk as low-cost natural adsorbent for removing turbidity. The effect of adsorbent dosage, concentration, $\mathrm{pH}$ and stirring time were investigated.

\section{Materials and methods}

\subsection{Preparation of Turbidity Solution}

Bentonite-clay-based turbid water was prepared by adding measured quantity of the clay to water at different concentrations $(0.5,1$, and 3$) \mathrm{g}$ for $1 \mathrm{~L}$ of distilled water. The suspension was mixed rapidly at $500 \mathrm{rpm}$ for 10 minutes and then mixed at $150 \mathrm{rpm}$ for one day, then let still for few hours to let the sellable particles to settle.

This process of preparing the synthetic water was repeated with the same concentrations and changing the targeted parameter to be measured.

The prepared water was transferred to "Lovibond" jar test equipment then moved to "Lovibond" TurbiDirect" to measure the turbidity each time. The process was repeated as illustrated throughout the paper to maintain a set of parameters and vary one of them.

\subsection{Preparation of adsorbent}

The experimented rice husk used was locally collected from an Iraqi rice mill. The rice husk was crushed, sieved to $\sim 0.150 \mathrm{~mm}$ in diameter, and washed with distilled water to remove impurities. The adsorbent was then dried by exposure to the sun light, and put in oven at $150^{\circ} \mathrm{C}$ for $3 \mathrm{hr}$. The dried husk was stored in desiccators until used. SEM imaging was done to the rice husk to study the surface morphology. The study aimed to check the irregularities resulted in the surface which reflects the magnitude of sorption.

\subsection{Kinetic Models}

To develop an appropriate sorption treatment processes, it is required to expect the rate at which sorbate is removed from the solutions in order (Puranik et al. 1999). The adsorption kinetics, thus, constitute a major principle in the determination of sorption processes (Wang et al. 2010). Three kinetic models are used in this study as shown below: (Naji et.al. 2019)(Saad et.al. 2019), and (Abd Ali, 2020)

Pseudo first order (Lagergren 1989)

$q_{t}=q_{e}\left(1-\mathrm{e}^{-k_{1} t}\right)$

Pseudo second order (Ho and McKay 1999)

$q_{t}=\frac{\mathrm{t}}{\left(\frac{1}{k_{2} q_{e}^{2}}+\frac{t}{q_{e}}\right)}$

where $k_{1}$ is the equilibrium rate constant of pseudo first order adsorption $(1 / \mathrm{min}), k_{2}$ is the rate constant of adsorption $(\mathrm{g} / \mathrm{mg} \mathrm{min})$, qt is the amount of contaminant adsorbed at time $t(\mathrm{mg} / \mathrm{g})$. The amount of sorbate retained onto the reactive material phase, $q_{e}$, can be calculated by:

$q_{e}=\left(C_{o}-C_{e}\right) \frac{\mathrm{V}}{m}$

where $m$ is the quantity of Rice husk added to the flask (g) and $\mathrm{V}$ is the volume of aqueous solution (L). Pseudo-first order and Pseudo-second order were used to curve fit the kinetic data obtained in the study. The method followed to extract the theoretical estimated data was the nonlinear regression method which is a standard processes available at Microsoft Excel 2016, for that reason no further verification was done.

\section{Results and Discussion 3.1 SEM analysis}

Scanning Electron Microscopy (SEM) image is taking for the adsorbent sample at a range of 50-500 $\mu \mathrm{m}$ as shown in Figure 1. The irregularity of the husk is confirmed as rough and smooth areas were observed throughout the tested samples. Sorption is expected even at smaller magnitude according to the small pores found around the edges. The SEM analysis was done at Al-Nahrain University. 

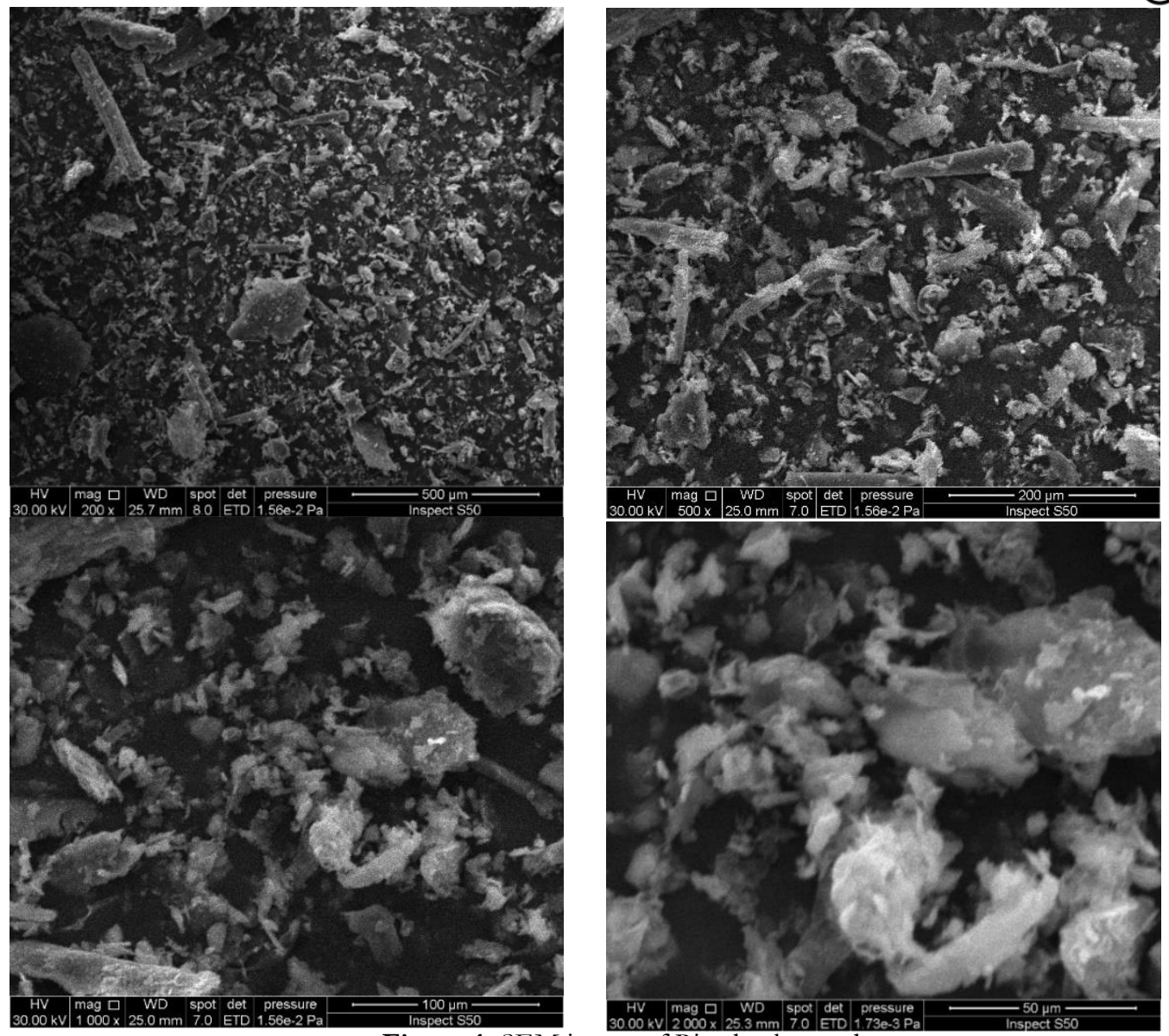

Figure 1: SEM image of Rice husk powder.

\subsection{Adsorbent dosage effect}

Rice husk dosage is an important parameter associated with turbidity removal studies. Therefore, the dosage parameter examines the potential of the Rice husk to remove the turbidity, the case study was done on a still turbid water. Different Rice husk dosage $(0.1-1.5 \mathrm{~g} / 100 \mathrm{~mL})$ was selected to study its effect on removal of turbidity as shown in Figure 2 (the range was chosen to match a previous study seeking similarity) (Zhang et.al. 2014). This figure shows a direct proportionality of the turbidity removal efficiency with respect to the Rice husk dosage, the efficiency peaked at $95 \%$ efficiency with husk dosage of $0.7 \mathrm{~g} / 100 \mathrm{~mL}$. This can be linked to the increase of the surface area of the adsorbent with increasing the dosage. The efficiency was observed declining when the rice husk dosage was increased in the range between $0.7 \mathrm{~g} / 100 \mathrm{~mL}$ and $1.5 \mathrm{~g} / 100 \mathrm{~m}$, however, the removal efficiency was found to be maintained above $85 \%$ in the tested range. This behavior can be explained by the rice husk itself has become a source of turbidity in the aqueous solution. Overdosing the Rice husk seed powder causes inadequate number of the turbid particles resulted from the re-stabilization of the destabilized particles which end up forming more inter-particle bridges (Faisal et.al., 2019). According to that, the optimum Rice husk dosage was $0.7 \mathrm{~g}$ $/ 100 \mathrm{~mL}$ and this dose was fixed throughout the study.

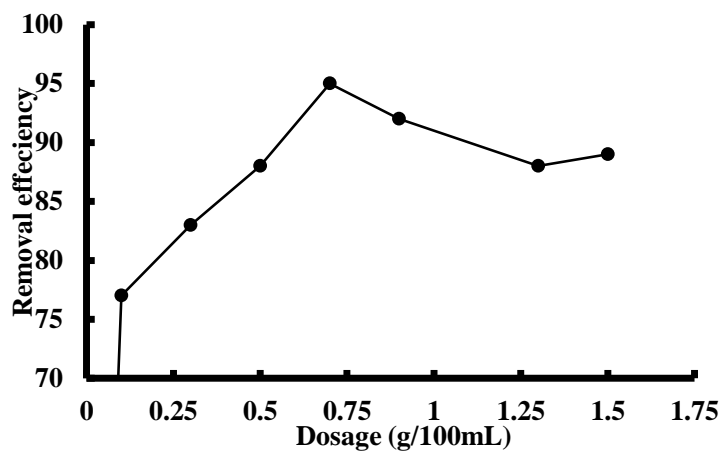

Figure 2: The dosage effect on turbidity removal efficiency (time $=3 \mathrm{hr} \mathrm{pH}=6$, agitation speed $=250 \mathrm{rpm}$, initial turbidity $=200 \mathrm{NTU}$ ).

\subsection{Effect of Concentration}

Bentonite suspensions synthetic turbid water was prepared based to coagulation tests. Different turbidities level was used at each trial $(80,120,170$, 200 , and $250 \mathrm{NTU}$ ) with a $0.7 \mathrm{~g} / 100 \mathrm{~mL}$ fixed Rice husk dosage, the $\mathrm{pH}$ level was tested in each time to be 6.0. The relationship between the initial turbidity and the turbidity removal efficiency is shown in Figure 3. This figure shows that the removal efficiency elevated from $67 \%$ to reach up to $92 \%$ when the turbidity was risen from 80 NTU to 200 NTU. Similar to the dosage effect, at concentrations higher than 200 NTU the efficiency dropped to $82 \%$, the reason of this drop is due to the increase in the number of the colloidal particles which results in more interaction between them. But at the lower concentration, 


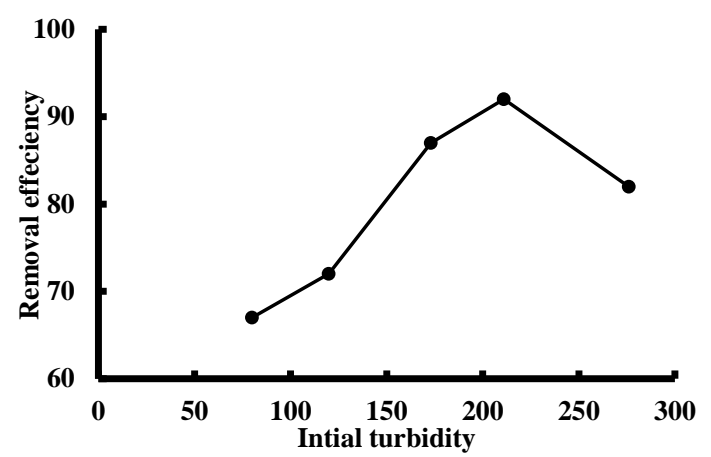

Figure 3: Effect of concentration on removal of turbidity (time $=3 \mathrm{hr}, \mathrm{pH}=6$, agitation speed $=250 \mathrm{rpm}$, dosage $=0.7 \mathrm{~g} / 100 \mathrm{~mL})$.

\subsection{Effect of $\mathrm{pH}$}

The acidity level is a key factor to the removal of the turbidities. The $\mathrm{pH}$ effect on the removal efficiency was investigated by varying the solution $\mathrm{pH}$ in the range 3.0 to 10.0 for an initial turbidity of 100 NTU and the Rice husk dosage was kept constant at $0.7 \mathrm{~g} / 100 \mathrm{~mL}$ (see Figure 4). Examining figure 4 shows that the efficiency decreased when the $\mathrm{pH}$ increases. This was very obvious in the test results as the maximum removal efficiency was at $\mathrm{pH}$ level 3 while the lowest efficiency was at $\mathrm{pH}=10$. A possible explanation of that is the decrease in the negative charge of the functional group on the rice husk which can effect negatively on the efficiency. Since the $\mathrm{pH}$ test did not return enough information about the effect of $\mathrm{pH}$ level it was decided to keep the $\mathrm{pH}$ level at 3 throughout the experimental work.

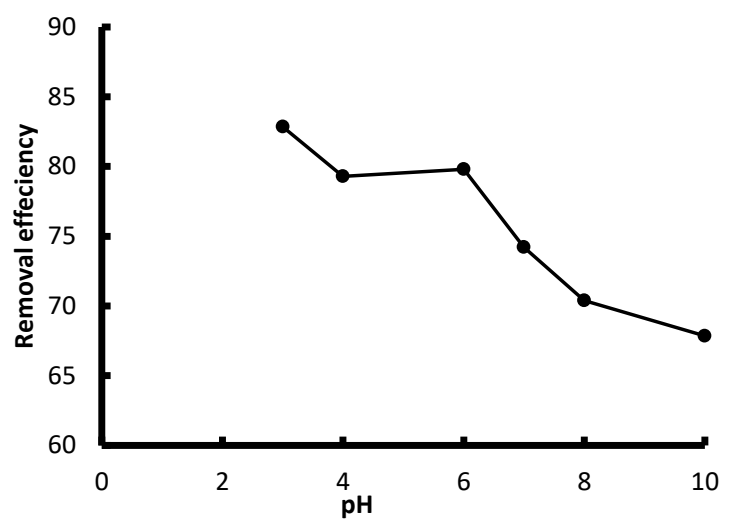

Figure 4: Effect of $\mathrm{pH}$ on removal of turbidity (time $=3 \mathrm{hr}, \mathrm{pH}=6$, agitation speed $=250 \mathrm{rpm}$, dosage $=0.7 \mathrm{~g} / 100 \mathrm{~mL}$ and initial turbidity $=$ 200 NTU).

\subsection{Effect of Stirring Time}

In this parameter, the conical flask containing solutions of bentonite and Rice Husk powder are subjected to different stirring times and the percentage removal of turbidity of the solutions is measured. The optimum stirring time value is determined by plotting a graph between removal efficiency versus the stirring time as reported in Figure 5. The test was done for the same dosage mentioned earlier $(0.7 \mathrm{~g} / 100 \mathrm{~mL})$ at room temperature. The figure shows a significant increase in the efficiency when the stirring time risen from 5 to 10. The efficiency is found to be maintained between $\sim 72 \%(\min )$ and $\sim 81 \%(\max )$ when the stirring time increased up to 60 .

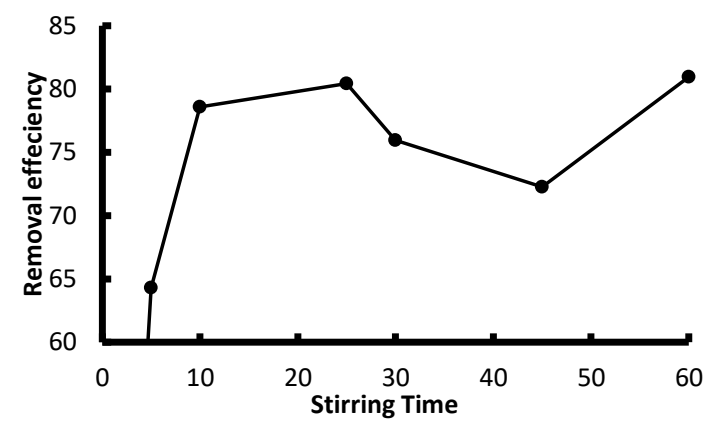

Figure 5: Removal efficiency of turbidity on Rice Husk as a function of contact time $(\mathrm{pH}=6$, agitation speed $=250 \mathrm{rpm}$, dosage $=0.7 \mathrm{~g} / 100 \mathrm{~mL}$ and initial turbidity $=200 \mathrm{NTU}$ ).

\subsection{FTIR analysis}

The functional groups of the silicon dioxide in Rice Husk power are determined through the Fourier Transfer- Infrared (FT-IR) analysis as shown in Figure 6. It showed two main regions $(1130-1000$ and $800-$ $400 \mathrm{~cm}^{-1}$ ). The bands between these two groups related to the -O-Si-O- $[5][6]$ and typical $\mathrm{SiO}_{2}$ structures, which can be considered as a reflection of silica. In the 1100-950 $\mathrm{cm}^{-1}$ region, significant interferences from silica and silicate derivatives is presented. The change of silica functional group hence the adsorption of turbidity.

\subsection{Adsorption Kinetics}

To support our case, kinetic data was extracted using the models presented in 2.3. This data was fitted and analyzed using the pseudo first-order and pseudosecond-order. The fitted data is shown in Figure 7. The constants are listed in Table 1, these models are found using nonlinear regression method available in Microsoft Excel 2016 (Brown 2001).

With $\mathrm{R}^{2}$ of 0.981 , it is obvious that the turbidity adsorption from the solution follows the Pseudosecond-order kinetic model. Comparing the calculated adsorbed pollutant density $(9.61 \mathrm{mg} / \mathrm{g})$ to the actual experimental values of $(9.714 \mathrm{mg} / \mathrm{g})$, this supports the theory that the adsorption process relies mainly on the chemisorption mechanism. 


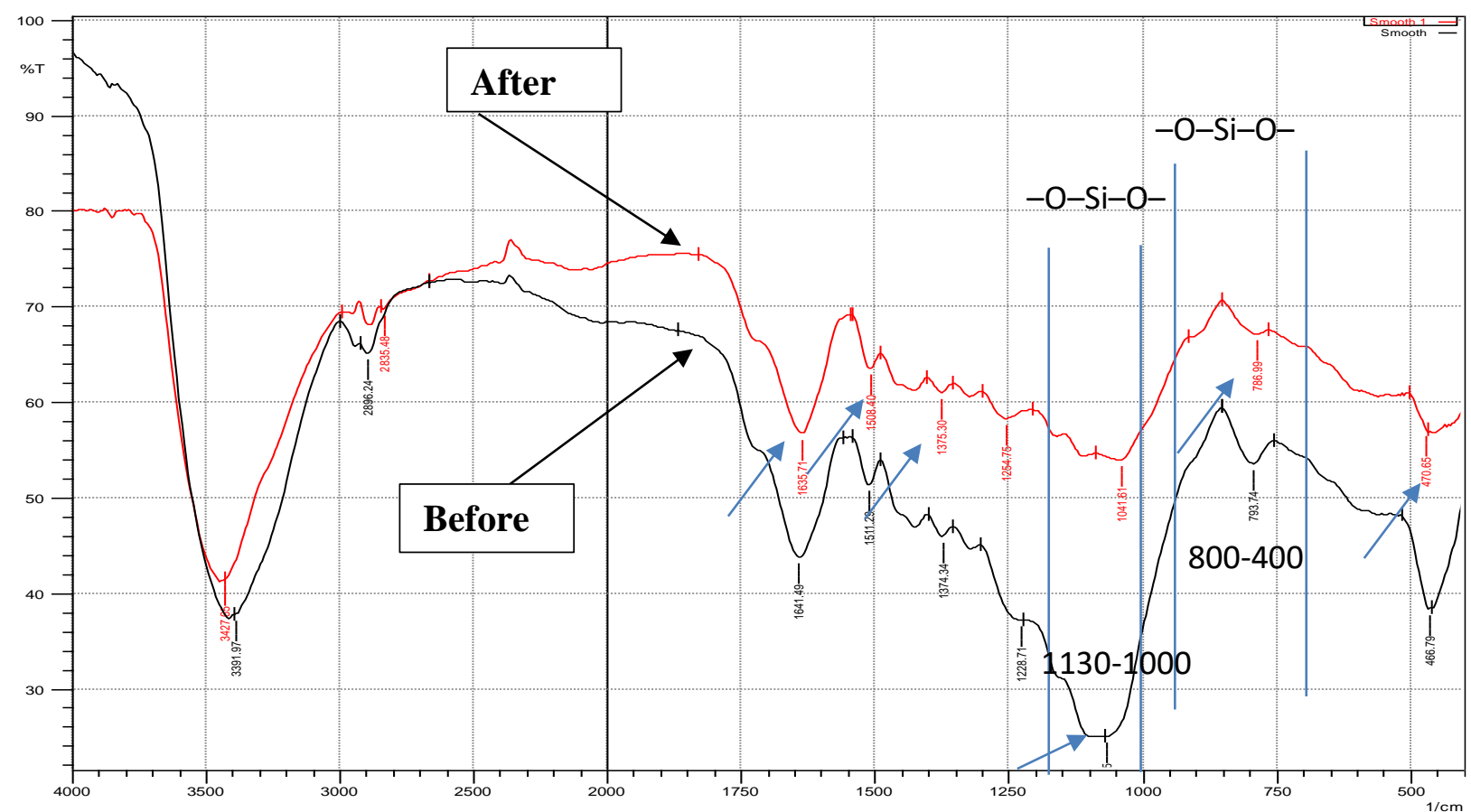

Figure 6: FTIR Analysis showing the behavior of the water absorption pattern compared to Silicate and silica groups

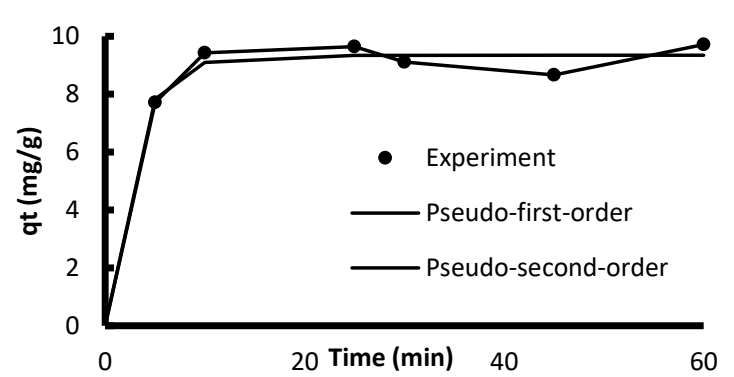

Figure 7: Kinetic models for sorption of turbidity onto Rice Husk $(\mathrm{pH}=6$, agitation speed $=250 \mathrm{rpm}$, dosage $=0.7 \mathrm{~g} / 100 \mathrm{~mL}$ and initial turbidity $=200$ NTU).

Table 1: Constants of kinetic models for sorption of turbidity onto Rice Husk

\begin{tabular}{|c|c|c|}
\hline Kinetic model & Parameter & Value \\
\hline \multirow{3}{*}{ Pseudo-first order } & $q_{e}(\mathrm{mg} / \mathrm{g})$ & 9.345 \\
\cline { 2 - 3 } & $k_{1}\left(\mathrm{~min}^{-1}\right)$ & 0.3629 \\
\cline { 2 - 3 } & $\mathrm{R}^{2}$ & 0.702 \\
\hline \multirow{2}{*}{$\begin{array}{c}\text { Pseudo-second } \\
\text { order }\end{array}$} & $q_{e}(\mathrm{mg} / \mathrm{g})$ & 9.61 \\
\cline { 2 - 3 } & $k_{2}(\mathrm{~g} / \mathrm{mg} \mathrm{min})$ & 0.109 \\
\cline { 2 - 3 } & $\mathrm{R}^{2}$ & 0.981 \\
\hline
\end{tabular}

\section{Conclusion}

In this paper experimental practices were followed to prove the efficiency of the rice husk as a cheap alternative adsorbent to reduce the turbidity of a synthetic turbid water is shown. A set of parameters including the adsorption dosage effect, concentration of bentonite-clay (forming the initial turbidity parameter), $\mathrm{pH}$ level, stirring time, were tested to optimize the turbidity reduction process. The maximum efficiency was found to be $95.36 \%$ when the optimum rice husk dosage $(0.7 \mathrm{~g} / \mathrm{ml})$ was used for turbidity concentration (bentonite-clay concentration) below 211NTU. On the other hand, considering a 100 NTU bentonite concentration it was noticed that the removal efficiency was $75 \%$ or more for the $\mathrm{pH}$ level between 2 and 7, nevertheless, the $\mathrm{pH}$ test did not return enough information about the behavior of the rice husk so the $\mathrm{pH}$ level was kept at 3 to obtain turbidity removal efficiency of more than $95 \%$.

These results prove the efficiency of rice husk as an adsorbent and opens more space to investigate about the process and how can it be transferred from the lab environment to the real-life application.

\section{References}

[1] Al-Baidhani, J. H. and Al-Salihy, S. T. (2016), "Removal of Heavy Metals from Aqueous Solution by Using Low Cost Rice Husk in Batch and Continuous Fluidized Experiments", International Journal of Chemical Engineering and Applications, Vol. 7, No. 1, February 2016

[2] Alwared, A. I. and Zeki, S. L., (2014), "Removal of Water Turbidity by using Aluminum Filings as a Filter Media", Journal of Engineering, vol. 20(7) .Pp103-114.

[3] Ramesh, N., Vennila, G, Ramesh, S., Magheshkumar, P. and Ram, S. M., (2016) "Efficacy of Natural Coagulants in Wastewater Treatment Aided with Solar Power", International Journal of Advanced Science and Engineering Research, vol. 1, Issue 1.

[4] Dhruva, Suresh B,(2016), " An Investigation of Effect of Natural coagulant (Tulsi) for reduction of $\mathrm{pH}$, Turbidity and COD from sewage water", International Research Journal of Engineering and Technology (IRJET), Vol. 03 Issue 07.

[5] Simons, R., (1993)," Trace element removal from ash dam waters by nanofiltration and diffusion dialysis", Desalination, 89, 325-341,

[6] Gandhi, N. , Sirisha, D. and Sekhar C.K.B., (2016)," Adsorption of Fluoride (F-) from Aqueous Solution by using Pineapple 
(Ananascomosus) Peel and Orange (Citrus sinensis) Peel Powders, International Journal of Environmental Bioremediation \& Biodegradation, vol. 4(2) ,Pp. 55-67.

[7] Gandhi, N., Sirisha, D., Shekar, C.K.B.and Asthana, S.,(2012), Removal of Fluoride from Water and Wastewater by using Low Cost Adsorbents", International Journal of Chem. tech Research, Vol.4, No.4, Pp 1646-1653.

[8] Yunusa UM, Ahmad IM, Attah C, Odoh CE, Kabiru M Y and Yunusa, I. (2017), "Cucurbita pepo Seed Powder Reduce the Turbidity of River Water" , Annals of Experimental Biology, vol.5 (2), Pp. 10-14

[9] John, B., Baig, U., Fathima, N., Asthana, S. and Sirisha, D., (2017), "Removal of Turbidity of Water by Banana Peel Using Adsorption Technology", Journal of Chemical and Pharmaceutical Research, 9(4), Pp.65-68.

[10] Syafalni, R.A., Abustan I.and Ibrahim, A.N.M. , (2013)," Wastewater Treatment using Bentonite, the Combinations of Bentonitezeolite, Bentonite-Alum, and Bentonite-Limestone as Adsorbent and Coagulant", International journal of environmental sciences vol. 4(3).

[11] Puranik, P.R.; Modak, J.M.; Paknikar, K.M. A comparative study of the mass transfer kinetics of metal biosorption by microbial biomass. Hydrometallurgy 1999, 52, 189-197.

[12] Wang, L.K.; Hung, Y.T.; Tay, S.T.L.; Tay, J.H. Handbook of Environmental Engineering: Environmental Bioengineering; Volume 11.; Springer, 2010;

[13] Lagergren, S. About the theory of so-called adsorption of soluble substances. K. Seventeen Hand 1989, 24:1-39.
[14] Ho, Y.S.; McKay, G. Pseudo-second order model for sorption processes. Process Biochem. 1999, 34, 451-465.

[15] Naji, L.A.; Jassam, S.H.; Yaseen, M.J.; Faisal, A.A.H.; Al-Ansari, N. Modification of Langmuir model for simulating initial $\mathrm{pH}$ and temperature effects on sorption process. Sep. Sci. Technol. 2019, 1-8.

[16] Saad, N.; Abd Ali, Z.T.; Naji, L.A.; AAH Faisal, A. Development of Bi-Langmuir model for description initial $\mathrm{pH}$ and temperature effects on the sorption of cadmium onto waste foundry sand. Environ. Eng. Res. 2019.

[17] Abd Ali, Z.T.; Naji, L.A.; Almuktar, S.A.A.A.N.; Faisal, A.A.H.; Abed, S.N.; Scholz, M.; Naushad, M.; Ahamad, T. Predominant mechanisms for the removal of nickel metal ion from aqueous solution using cement kiln dust. J. Water Process Eng. 2020, 33, 101033.

[18] Faisal, A.A.H.; Naji, L.A. Simulation of Ammonia Nitrogen Removal from Simulated Wastewater by Sorption onto Waste Foundry Sand Using Artificial Neural Network. Assoc. Arab Univ. J. Eng. Sci. 2019, 26, 28-34.

[19] Zhang, Y.; Zhao, J.; Jiang, Z.; Shan, D.; Lu, Y. Biosorption of $\mathrm{Fe}(\mathrm{II})$ and $\mathrm{Mn}(\mathrm{II})$ Ions from Aqueous Solution by Rice Husk Ash. Biomed Res. Int. 2014, 2014, 1-10.

[20] E. Fataei, E. M. Moghaddam, and M. Abdollahzadeh, Determination of the Best Coagulant for Turbidity and Organic Matter Removal in the Coagulation Process of Ardabil Water Treatment Plant in Iran, Advances in Environmental Biology, 8(22), Nov. 2014, 319324. 